\title{
CRONOLOGIA E IMPACTO AMBIENTAL DO USO DA TERRA NA MICROBACIA HIDROGRÁFICA DO CEVEIRO, EM PIRACICABA, SP1
}

\author{
PETERSONRICARDO FIORIO ${ }^{2}$, JOSÉ ALEXANDRE MELO DEMATTÊ ${ }^{3}$ e GERD SPAROVEK ${ }^{3}$
}

\begin{abstract}
RESUMO - Este trabalho objetivou avaliar a cronologia e o impacto ambiental do uso da terra na Microbacia Hidrográfica do Ceveiro (MHC), nos anos de 1962, 1965, 1978 e 1995. Utilizou-se a fotointerpretação e geoprocessamento, o que permitiu uma rápida e eficiente integração entre os dados levantados. Os solos da área são basicamente Litossolos e Podzólicos Vermelho-Amarelos. A cultura anual, que em 1965 chegou a ocupar 42\% da área da microbacia, em 1995 ocupava $0,15 \%$. Nesse mesmo período, o plantio da cana-de-açúcar passou de $16 \%$ para $66 \%$, sendo esta cultura a principal causa da diminuição das culturas anuais na microbacia. O maior aumento do plantio da cana-de-açúcar ocorreu de 1978 a 1995, caracterizando, assim, a influência dos incentivos governamentais para o seu cultivo. As pastagens e os reflorestamentos também contribuíram para a expansão do plantio da cana-de-açúcar, com uma diminuição em área de $48 \%$ das pastagens e $42 \%$ do reflorestamento. As áreas de mata nativa e urbana apresentaram um aumento de 1962 a 1995. O impacto ambiental na MHC tem como indicador a represa da Vila de Artemis, que, de 1978 a 1995, diminuiu sua área em 50\%, em decorrência do assoreamento.
\end{abstract}

Termos para indexação: fotointerpretação, sensoriamento remoto, cana-de-açúcar, sistema de informações geográficas.

\author{
CRONOLOGY AND ENVIRONMENTAL IMPACT OF LAND \\ USE ON CEVEIRO MICROBASIN IN PIRACICABA REGION, BRAZIL
}

\begin{abstract}
The objective of this work was to evaluate the chronology and environmental impact of the land use on Ceveiro Microbasin, in Piracicaba, São Paulo State, during the years of 1962, 1965, 1978 and 1995. Photointerpretation and geoprocessing were used, allowing a fast and efficient integration of the data. The soils of the area are basically Entisols and Ultisols. Annual crops that in 1965 occupied 42\% of the Microbasin area, in 1995 occupied $0,15 \%$. In that same period, sugarcane passed from $16 \%$ to $66 \%$, causing the decrease of the annual crops. The largest growth of sugarcane crop occurred from 1978 to 1995 , characterizing the influence of the government incentives for its cultivation. Pastures and reforestations also contributed to the expansion of sugarcane, with a decrease in area of $48 \%$ for pastures and $42 \%$ for reforestation. Native forest and urban areas presented an increase from 1962 to 1995 . The environmental impact in the Ceveiro Microbasin is indicated by Vila de Artemis dam, that from 1978 to 1995 decreased its area in 50\% due to silting.
\end{abstract}

Index terms: photointerpretation, remote sensing, sugarcane, geographic information system.

\footnotetext{
${ }^{1}$ Aceito para publicação em 3 de maio de 1999.

Extraído da Dissertação de Mestrado, apresentada pelo primeiro autor à ESALQ/USP, em Piracicaba, SP.

${ }^{2}$ Eng. Agrôn., M.Sc., Pós-Graduando do curso de Solos e Nutrição de Plantas, ESALQ/USP, Caixa Postal 09, CEP 13418-900 Piracicaba, SP. E-mail: prfiorio@carpa.ciagri.usp.br

${ }^{3}$ Eng. Agrôn., Dr., Dep. de Solos e Nutrição de Plantas, ESALQ/USP. E-mail: jamdemat@carpa.ciagri.usp.br, gsparove@carpa.ciagri.usp.br
}

\section{INTRODUÇÃO}

O uso constante do solo e de tecnologias de ponta nem sempre levam em consideração os manejos mais adequados desses recursos, o que vem a promover maior desgaste e empobrecimento do meio físico. Dessa forma, com o passar dos tempos, o homem vem procurando encontrar um ponto de equilíbrio entre o uso racional dos recursos naturais e da 
produtividade. Porém, em muitas áreas os fatores econômicos prevalecem sobre a potencialidade do meio.

Uma das áreas de grande crescimento econômico do Estado de São Paulo é a região de Piracicaba, que dispõe de um dos principais parques industriais do Brasil, extremamente diversificado e moderno. Nesta região, o plantio da cultura de cana-de-açúcar sempre foi muito estimulado, principalmente após o Proalcool, em 1973, acarretando um aumento expressivo das usinas de moagem na região, bem como da mão-de-obra empregada. Com este estímulo, no município de Piracicaba, o plantio de cana-de-açúcar substituiu em torno de 24.000 ha de pastagens e pouco mais de 3.000 ha de áreas com outras atividades. Em 1962, a cultura canavieira ocupava 35\% da área do município, passando para 50\% em 1991. As áreas de pastagens foram as que mais cederam terras para esta expansão, diminuindo de 43\%, em 1962, para 25\%, em 1991 (Sparovek \& Lepsch, 1995). Ainda segundo os autores, esta expansão ocorreu principalmente em solos de maior erodibilidade, uma vez que as terras de maior potencial agrícola já eram ocupadas com a cultura de cana-de-açúcar antes de 1962.

Politano et al. (1983), com utilização de fotografias aéreas, detectaram que a ocupação da cultura de cana-de-açúcar no município de Jaboticabal pode estar associada às condições distintas de solo e relevo, influência da localização da área em relação à proximidade de usinas de açúcar e álcool e incentivos governamentais, sendo estes os grandes responsáveis por mudanças expressivas nos canaviais da região.

A Microbacia Hidrográfica do Ceveiro, localizada no município de Piracicaba, vem sendo utilizada por muitos anos com o plantio da cultura de cana-deaçúcar, devido à proximidade da usina de processamento, sendo também responsável pelo abastecimento de água potável para aproximadamente 2.000 habitantes. É muito provável que a ocupação desordenada do plantio de cana-de-açúcar na região, em virtude de incentivos governamentais (Proalcool), tenha acarretado problemas de ordem ambiental.

O objetivo deste trabalho foi o de avaliar a cronologia da ocupação da terra na Microbacia
Hidrográfica do Ceveiro nos anos de 1962, 1965, 1978 e 1995, pelo uso da fotointerpretação, verificando os possíveis impactos desses usos e manejos sobre o ambiente.

\section{MATERIAL E MÉTODOS}

A Microbacia Hidrográfica do Ceveiro, situada a $22^{\circ} 40^{\prime} \mathrm{S}$ e $47^{\circ} 47^{\prime} \mathrm{W}$ no município de Piracicaba, SP, constitui uma superfície de aproximadamente 1.990 ha, com vegetação natural composta por floresta mesófila semidecídua e clima mesófilo úmido subtropical ( $\mathrm{Cwa}$ ), segundo o sistema Köppen, com período chuvoso compreendendo os meses de outubro a março, com precipitação média de $162,7 \mathrm{~mm}$, e período seco compreendendo os meses de abril a setembro, com precipitação média de $46 \mathrm{~mm}$. A geologia da bacia está representada por rochas relacionadas com a formação Corumbataí do Grupo Passa Dois (siltitos, argilitos e folhelhos cinzentos a roxos, que dão origem a cerca de $67 \%$ dos solos da bacia), com arenitos da formação Pirambóia e com as intrusivas básicas (formação Serra Geral), ambas pertencentes ao Grupo São Bento (Instituto de Pesquisas Tecnológicas, 1981).

O relevo caracteriza-se por apresentar morros em cotas variando entre 460 e $580 \mathrm{~m}$ de altitude, com classes ondulado a forte ondulado. A declividade predominante nas encostas é de $10 \%-15 \%$ e nos topos de $5 \%$. As áreas com declividades menores que $2 \%$ encontram-se em pequenas várzeas e topos de alguns morros, constituindo menos de $5 \%$ da área total.

A área apresenta sete classes de solo (Fig. 1): Podzólico Vermelho-Amarelo, Terra Roxa Estruturada, Terra Roxa Estruturada Podzólica, Podzólico Vermelho-Escuro, Litólicos, Cambissolos, Solos Hidromórficos e Solos Aluviais (Sparovek, 1991).

Foram utilizadas fotografias aéreas pancromáticas (preto e branco) verticais, dos anos de 1962, na escala aproximada 1:25.000; de 1965, na escala aproximada de 1:60.000; de 1978 , na escala aproximada de 1:35.000 e de 1995, na escala aproximada de 1:25.000. A interpretação das fotografias aéreas foi realizada segundo metodologia descrita por Rabben (1960), que inicia pela delimitação da área útil ou efetiva de cada fotografia. Posteriormente, foram utilizadas técnicas de overlay produzidos com folhas de acetato transparente com 0,10 milímetro de espessura, para a confecção dos mapas de uso (Anderson, 1982).

Os mapas de uso da terra gerados foram digitalizados e exportados para o Sistema de Informações Geográficas (SIG) Idrisi (Eastman, 1992), conforme mostra a Fig. 2. 


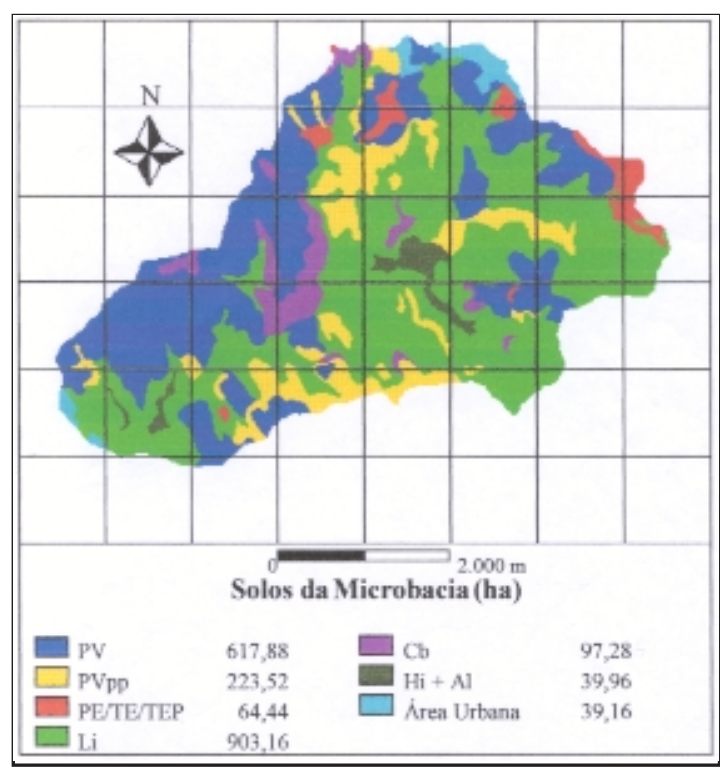

FIG. 1. Representação do mapa pedológico reagrupado da área de estudo.

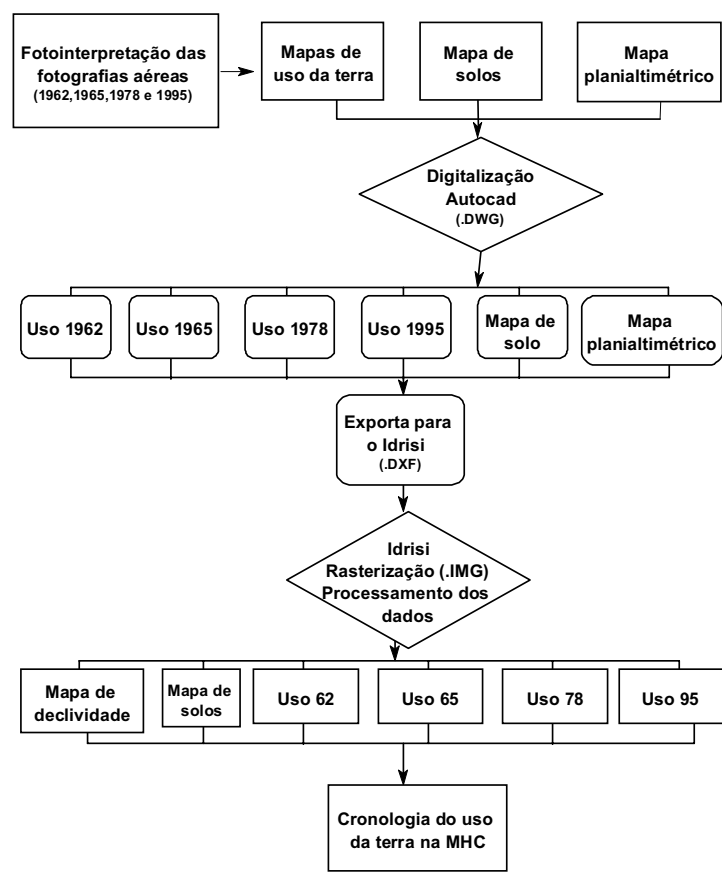

FIG. 2. Método utilizado para a obtenção da cronologia do uso da terra na Microbacia Hidrográfica do Ceveiro.

\section{RESULTADOS E DISCUSSÃO}

\section{Fotointerpretação do uso da terra}

Em relação às diferentes escalas, verificou-se que as fotografias de escala 1:35.000 foram as que mais facilitaram a interpretação do uso da terra no ano de 1978, pois o mapa gerado foi o mais enriquecido em detalhes. Da mesma forma, o trabalho em fotografias de escala 1:25.000 também facilitou a interpretação, gerando um bom nível de detalhamento para os anos de 1962 e 1995; essas informações são condizentes com trabalhos realizados por Koffler et al. (1979) e Borges et al. (1993), que verificaram que a utilização de fotografias aéreas na escala 1:35.000, proporcionaram um bom nível de detalhamento para semelhantes finalidades.

Nas fotografias aéreas 1:60.000, observaram-se perdas de detalhes do uso da terra, principalmente para matas ciliares e matas próximas a canais de drenagem. Demétrio (1977) verificou perda de detalhamento da rede de drenagem na escala 1:60.000, justificando a perda de detalhamento das matas, geralmente localizadas nesses canais.

\section{Cronologia do uso da terra na Microbacia Hidrográfica do Ceveiro}

A cultura de cana-de-açúcar foi a que mais aumentou em toda a área, pois em 1962 ocupava 16\% da microbacia, e em 1995 passou a ocupar 66\% (Tabela 1).

Tal aumento foi mais significativo nos anos de 1978 e 1995, atingindo 40\% do total da área. Um dos fatores responsáveis por esse aumento foi o Programa Proalcool, implantado em 1973, que buscava certa substituição da gasolina pelo álcool. Outro fato que contribuiu foi a proximidade de uma usina de moagem localizada ao noroeste da área (Fig. 3). Politano et al. (1983) constataram, por intermédio de fotografias aéreas da região de Monte Alto, SP, mudanças representativas nas áreas canavieiras, decorrentes dos dois fatores anteriormente citados.

Conforme mostra a Fig. 3, este aumento em 1978 ocorreu principalmente nos solos Litólicos, de maior suscetibilidade à erosão (Fig. 1), em consonância com estudos realizados por Sparovek \& Lepsch (1995), na região de Piracicaba, que verifi- 
caram que a expansão da cultura de cana-de-açúcar ocorreu principalmente em solos de maior erodibilidade, uma vez que as terras de maior potencial agrícola já eram ocupadas pela cultura antes de 1962.

As pastagens também cederam áreas para a expansão da cultura canavieira, que em 1962 ocupavam 29\% da superfície, e em 1995 passaram a ocupar $14 \%$, ou seja, houve uma diminuição de $48 \%$ de áreas com pastagem (Tabela 1). Sparovek \& Lepsch (1995) também constataram que as áreas de pastagens foram as mais substituídas, em virtude dessa expansão, diminuindo de $43 \%$ da área, em 1962, para 25\% da área em 1991.

Em 1978, as áreas com pastagem ocupavam 42\% do total (Tabela 1), e tiveram sua maior queda com o aumento das áreas do plantio de cana-de-açúcar, de 1978 para 1995 (Fig. 3). Borges et al. (1993) verificaram não haver diferenças nas áreas ocupadas pelo plantio de cana-de-açúcar entre 1978 e 1991, na região de Santa Bárbara D’Oeste.

O crescimento urbano teve preferência pelas áreas de pastagem e cultura anual (Fig. 3), principalmente de 1978 a 1995. Essas informações conferem com estudos realizados por Borges et al.(1993) em que os autores constataram um aumento das áreas urbanas sobre áreas de pastagem e de culturas anuais. A área urbana teve um aumento de 7\% de 1962 a

TABELA 1. Dimensão (\%) das áreas de uso da terra na Microbacia Hidrográfica do Ceveiro no período de 1962 a 1995.

\begin{tabular}{lrrrc}
\hline Uso da terra & \multicolumn{4}{c}{ Ano/Escala } \\
\cline { 2 - 5 } & 1962 & 1965 & 1978 & 1995 \\
& $1: 25.000$ & $1: 60.000$ & $1: 35.000$ & $1: 25.000$ \\
\hline Cana-de-açúcar & 16,00 & 7,60 & 26,40 & 66,30 \\
Cultura anual & 31,80 & 42,00 & 11,40 & 0,15 \\
Pasto & 14,60 & 14,20 & 28,10 & 4,84 \\
Pasto Sujo & 14,50 & 12,40 & 14,20 & 9,11 \\
Reflorestamento & 14,20 & 11,60 & 13,50 & 6,03 \\
Mata & 2,30 & 1,60 & 1,60 & 6,74 \\
Mata ciliar & 6,40 & 10,20 & 3,80 & 4,59 \\
Área urbana & 0,10 & 0,40 & 0,60 & 1,97 \\
Cultura perene & 0,10 & 0,00 & 0,00 & 0,00 \\
Represa & 0,00 & 0,00 & 0,60 & 0,28 \\
\hline Total & 100,00 & 100,00 & 100,00 & 100,00 \\
\hline
\end{tabular}

1995, que deve ter sido decorrente da maior necessidade de mão-de-obra para o plantio da cana-de-açúcar. Borges et al. (1993) também verificaram um aumento na área urbana no município de Santa Bárbara d'Oeste, nas proximidades das áreas cultivadas com a cana-de-açúcar.

As culturas anuais em 1962 ocupavam cerca de $32 \%$ da área de estudo; em 1995 passou a ocupar apenas $0,15 \%$, ocorrendo uma diminuição de $99 \%$ da área plantada. É importante ressaltar que em 1962 a cultura de milho constituía grande parte das culturas anuais, e veio perdendo espaço para a cana-deaçúcar, principalmente no ano de 1978 (Fig. 3). Esses resultados diferem dos obtidos por Sparovek \& Lepsch (1995), pois segundo os autores a pastagem na região de Piracicaba foi a que mais cedeu áreas para a expansão do plantio da cana-de-açúcar.

O reflorestamento em 1962 ocupou 14\% da área total, e em $19956 \%$ da área total, diminuindo $42 \%$ (Tabela 1). A mata nativa apresentou aumento de $33 \%$, passando de $2,3 \%$ em 1962 para $6,7 \%$, em 1995 , principalmente nas proximidades da rede de drenagem, o que vem a confirmar o cumprimento da Lei no 4171/BR de 15.9.1965, artigo 2o- que determina a preservação permanente das florestas e demais formas de vegetação natural situados ao longo de rios ou de outro qualquer curso de água (Fig. 3).

Outro fato importante está associado à represa do Córrego do Ceveiro, que foi projetada para fornecer água potável para a Vila de Artemis. Essa represa ocupava cerca de $0,6 \%$ da área, em 1978, mas devido a processos erosivos passou a ocupar apenas $0,3 \%$ da área em 1995, ou seja, houve uma diminuição de $50 \%$, em razão da alta suscetibilidade dos solos Li e PV, que favoreceram o assoreamento da represa. Atualmente a represa do Córrego do Ceveiro encontra-se desativada e não fornece mais água para a vila.

\section{Evolução do uso da terra em função das clas- ses de solo}

A maior parte das culturas anuais, em 1962, ocupava principalmente os solos Litólicos (Li), correspondente a $54 \%$ da área. Os solos com Horizonte B textural perfaziam um total de $42 \%$, do qual o solo Podzólico Vermelho-Amarelo (PV) foi o mais representativo, com $24 \%$ da área. Os $4 \%$ restantes esta- 
vam divididos entre os Cambissolos $(\mathrm{Cb})$, com 1,8\%, e os Hidromórficos mais Aluviais ( $\mathrm{Hi}+\mathrm{Al})$, com 2,2\% da área (Fig. 4).

Em 1965, os solos Li ainda eram a principal classe de solo ocupada pela cultura anual, com $53 \%$ da área. Os solos PV mantiveram-se com $42 \%$ da área, sendo o restante dividido entre os outros solos. Em 1978, os solos PV predominavam com 56\% da área ocupa- da, e os solos Li passaram a ocupar $40 \%$ da área. Em 1995, com a expansão do plantio da canade-açúcar, as culturas anuais passaram a ocupar apenas 2,9 ha (Fig. 4), com predomínio dos solos Li.

Em todos os anos estudados a cultura anual encontrou-se cultivada principalmente nos solos Litólicos e Podzólicos sob relevo ondulado. Tais informações não estão de acordo com os dados apre-
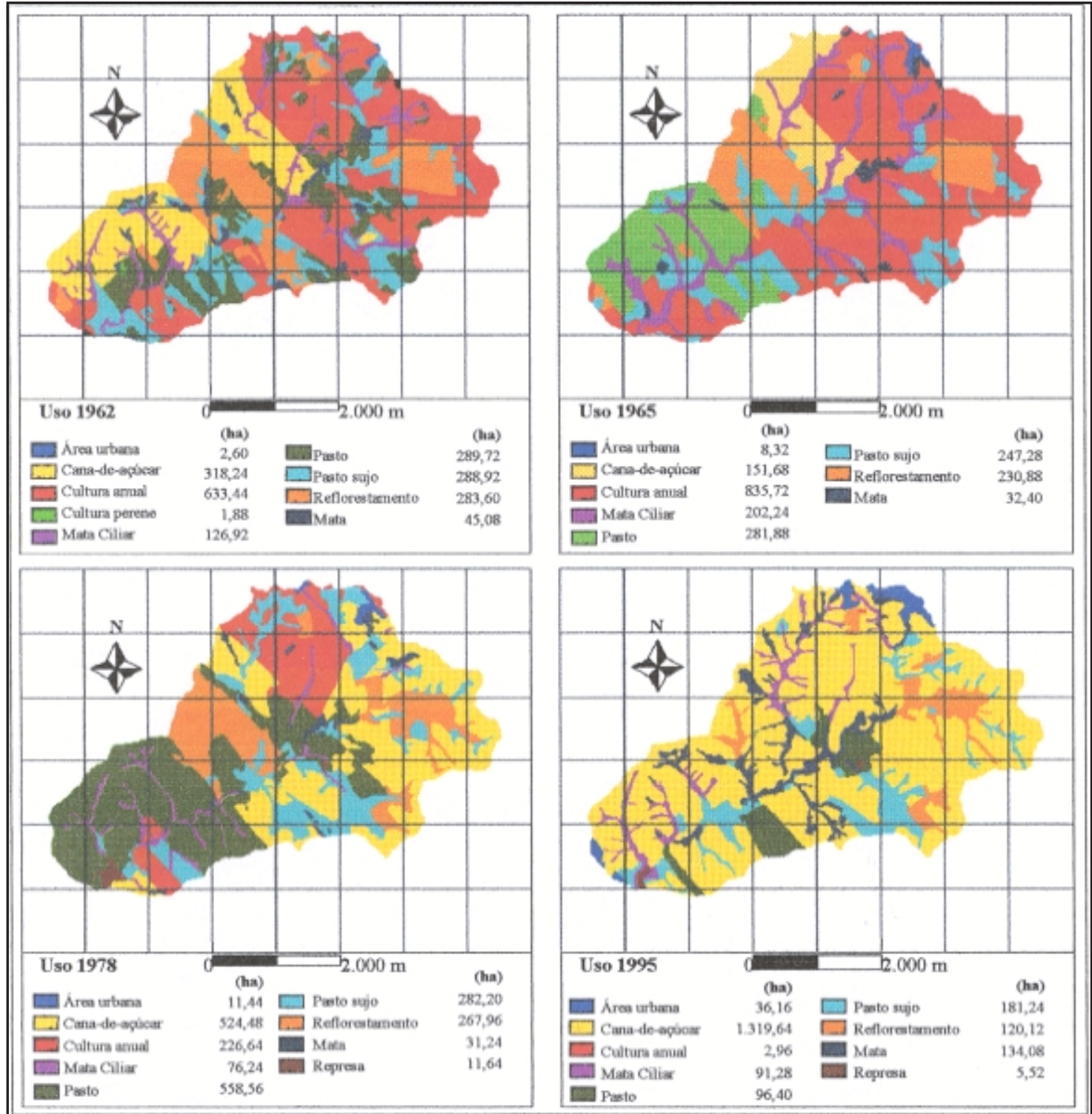

FIG. 3. Cenários do uso da terra na Microbacia Hidrográfica do Ceveiro. 
P.R. FIORIO et al.
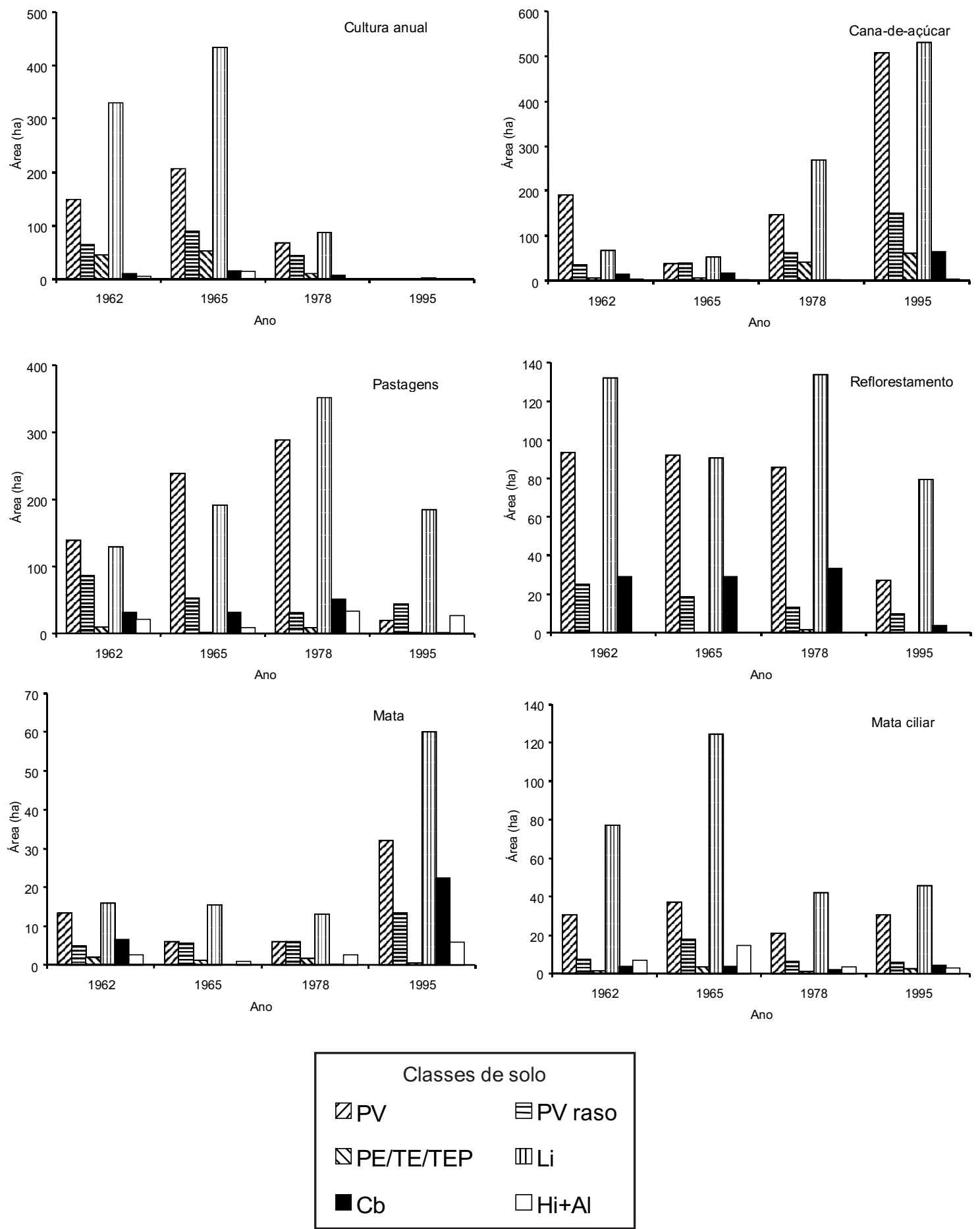

FIG. 4. Cronologia do uso da terra na microbacia com os respectivos solos. 
sentados por Flores (1995), que considera que para esses solos sob fortes declives o uso mais adequado seja reflorestamento e matas. Pinto et al. (1989) consideram os solos Li e PV, do grupo de aptidão V, como inaptos ou de aptidão restrita para culturas anuais, pela alta suscetibilidade à erosão.

A área plantada em 1962 com a cultura da canade-açúcar no PV era de 191,08 ha (Fig. 4). Em 1995, com a expansão do plantio da cana-de-açúcar, a mesma apresentava-se com 38\% do total da cultura com PV na Microbacia Hidrográfica do Ceveiro (Fig. 4).

Em 1962, a cultura da cana-de-açúcar ocupava 21\% das áreas de solos Li; em 1995, a área plantada na mesma classe de solo aumentou cerca de oito vezes, ocupando $40 \%$ da área total com a cultura (Fig. 4). Segundo Vieira (1987), os PV apresentam aptidão para pastagens e culturas de ciclo longo (cana-de-açúcar), com o manejo correto para diminuir problemas de erosão, dada sua alta erodibilidade. Nota-se que o solo PV em 1962 era o mais utilizado para o plantio da cana-de-açúcar. A partir de 1978, verificou-se um aumento nas áreas cultivadas nos solos $\mathrm{Li}$, principalmente a noroeste da microbacia. A parte noroeste da microbacia encontra-se a $3 \mathrm{~km}$ da usina de moagem, o que tornara os solos Li de especial interesse, pela diminuição nos custos da produção e aumento do valor econômico, apesar de inaptos ou de uso restrito, pela alta erodibilidade (Sparovek \& Lepsch, 1995). Politano et al. (1983) também verificaram um aumento das áreas com cana-deaçúcar próximas à usina de açúcar e álcool.

Em 1962, as áreas de pastagem encontravam-se cultivadas principalmente sobre os solos com horizonte B textural (PV, PV raso e PE/TE/TEP), perfazendo um total de $56 \%$ da área. Os solos $\mathrm{PV}$ apresentavam 33\%, e os solos Li, 31\% do total da área com pastagem. Em 1965, os solos PV apresentavam-se com $45 \%$, e os solos Li com $36 \%$ do total de pastagens (Fig. 4). Os solos PV, em 1978, perfaziam 38\% do total, e os solos Li passaram a ser a principal classe de solo com pastagem com $46 \%$.

Por outro lado, em 1995 apenas 7\% dos solos PV eram ocupados por pastagens, enquanto os solos Li mantiveram-se como os principais solos sob pastagem, com $66 \%$ do total de pastagens e $20 \%$ do total de Li (Fig. 4), o que concorda com Vieira (1987), o qual considera a pastagem e reflorestamento como os mais indicados usos para solos $\mathrm{Li}$, dada a sua alta suscetibilidade à erosão.

Os solos $\mathrm{Hi}+\mathrm{Al}$ praticamente não alteraram o uso com pastagens no período de 1962 a 1995 (Fig. 4). Para Coelho (1974), os solos Hi e Al decorrem da deposição recente, no Quaternário, que apresentam problemas de drenagem, e devem ser ocupados com mata ciliar, dada a proximidade da drenagem, o que difere do uso atual na microbacia. O valor baixo de 8,12 ha de pastagem em 1965 deve estar relacionado à perda do detalhamento provocado pela escala 1:60.000, o que está de acordo com trabalhos realizados por Borges et al. (1993).

O reflorestamento, em 1962, ocupava 280,2 ha (Fig. 3), dos quais 47\% em solos Li, 33\% sobre PV, 9\% sobre os PV raso e 11\% sobre os Cb (Fig. 4).

Em 1965, o reflorestamento ocupava uma área de 229,8 ha, dos quais cerca de $40 \%$ da área eram utilizados com PV. Os solos Li ocupavam 39\% do total de reflorestamento. Dos $21 \%$ restantes, os $\mathrm{Cb}$ corresponderam a $12 \%$, e o solo PV raso englobava 9\% do total (Fig. 4). Em 1978, aos solos Li correspondiam a $50 \%$ das áreas plantadas (Fig. 4). Os solos PV ocupavam $32 \%$ do total de reflorestamento e $14 \%$ do total desse solo, $12 \%$ eram ocupados pelos solos $\mathrm{Cb}$, e $6 \%$ pelos solos PV raso. Em 1995, o reflorestamento ocupava 120 ha, dos quais cerca de $66 \%$ em solos Li, $23 \%$ nos PV, $8 \%$ sobre os solos PV raso, e 3\% sobre os solos Cb (Fig. 4).

Observa-se que, até 1978, com o aumento da cana-de-açúcar, a retirada do reflorestamento deu-se principalmente nos solos PV, mantendo-se a cultura sobre os solos Li e $\mathrm{Cb}$, o que concorda com Vieira (1987) e Flores (1995), para os quais os solos Li podem ser utilizados para reflorestamento e pastagens. Em 1995, a cana-de-açúcar invadiu também as áreas de solos $\mathrm{Li}$ e $\mathrm{Cb}$, que eram utilizadas com reflorestamento, promovendo, assim, maior risco de erosão.

Os principais solos ocupados por mata nativa, em todos os anos de estudo, foram os solos Li e os solos PV (Fig. 4). Ambos são altamente suscetíveis à erosão, apresentando-se, segundo Flores (1995), adequados para áreas de preservação, quando em declives acentuados.

Os solos Li em 1962 apresentavam uma área com mata nativa de 16 ha, $1,8 \%$ do total da área desse 
solo (Fig. 1), e 36\% do total das matas (Fig. 4). Em 1965 , mantiveram-se aproximadamente com os mesmos valores. Em 1978, a área total das matas mantivera-se em torno de 29 ha, sendo 13 ha sobre os solos Li. Em 1995, as matas passaram a ocupar 7\% do total dos solos Li (Fig. 4).

Os solos PV eram ocupados, em 1962, com 13 ha de matas $(2 \%$ do total desse solo e $29 \%$ do total de matas). Em 1965 e 1978 não houve mudanças significativas das matas em relação ao PV, sendo 6 ha de mata sobre esse solo, o que pode ser atribuído à escala de trabalho no ano de 1965, que apresentou menor detalhamento em comparação com a de 1:35.000, em 1978, condizendo com observações de Demétrio (1977) e Borges et al. (1993).

A principal classe de solo constatada sob mata ciliar foi o solo Li. Segundo Flores (1995), solos Litólicos em áreas de declive ondulado e forte ondulado são adequados a tal tipo de uso. A mata ciliar, em 1962, ocupava uma área de 126,9 ha, $60 \%$ do total sobre solo $\mathrm{Li}$ ( $8 \%$ desses solos), cerca de $24 \%$ do total da mata ciliar sobre solos PV ( $5 \%$ desses solos), e os $16 \%$ restantes divididos entre as outras classes de solos da área estudada (Fig. 4). Em 1965, 201,7 ha eram ocupados pela mata ciliar, $62 \%$ da área com solos Li, e 18\% sobre solos PV. Em 1978, 75 ha eram ocupados pela mata ciliar, sendo $56 \%$ sobre solos Li e $27 \%$ sobre solos PV (Fig. 4). Em 1995, a mata ciliar ocupava uma área de 91 ha, 50\% sobre solos Li e 33\% sobre solos PV. De 1962 a 1995, ocorreu uma diminuição das matas ciliares da ordem de $72 \%$. Por outro lado, muitas dessas áreas passaram a apresentar uma vegetação mais densa, sendo designadas como mata. Tal fato pode ser observado principalmente entre os anos de 1978 e 1995 (Fig. 3).

\section{CONCLUSÕES}

1. As escalas 1:35.000 do ano de 1978 e 1:25.000 dos anos de 1962 e 1995 são as escalas que mais facilitam a interpretação dos dados e enriquecem em detalhes os mapas gerados.

2. A cana-de-açúcar é a principal causa da diminuição das áreas de culturas anuais, pastagens e reflorestamento na Microbacia do Ceveiro; a dimi- nuição das áreas de pastagens e reflorestamento favorece a expansão da mata nativa e área urbana.

3. O aumento nas áreas de mata nativa e manutenção das matas ciliares durante os anos estudados mostra que a Lei $\mathrm{n}^{\mathrm{0}}$ 4771/BR de 15.09.65 foi obedecida.

4. A expansão desordenada da cana-de-açúcar, que leva em consideração aspectos econômicos, sem preocupação com a aptidão das terras, causa impacto ambiental negativo.

\section{REFERENCIAS}

ANDERSON, P.S. Fundamentos para fotointerpretação. Rio de Janeiro : Sociedade Brasileira da Cartografia, 1982. 136p.

BORGES, M.H.; PFEIFER, R.M.; DEMATTÊ, J.A.M. Evolução e mapeamento do uso da terra, através de imagens aerofotogramétricas e orbitais em Santa Bárbara D'oeste (SP). Scientia Agricola, Piracicaba, v.50, n.3, p.365-371, 1993.

COELHO, A.G.S. Variação decenal do uso agrícola das terras. Campinas : Instituto Agronômico, 1974. 32p. (IAC. Boletim Técnico, 11).

DEMÉTRIO, V.A. Variação de características de redes de drenagem em função da escala das fotografias aéreas verticais. Piracicaba : USP-ESALQ, 1977. 107p. Dissertação de Mestrado.

EASTMAN, J.R. Idrisi: user guide. Worcester : Clark University, 1992. 384p.

FLORES, M.X. Uso agrícola do solo: principais tipos de solo, potencial de utilização e impactos ambientais In: TAUK-TORNISIELO, S.M.; GOBBI, N.; FORESTI, C.; LIMA, S.T. (Eds.). Análise ambiental: estratégias e ações. São Paulo : Fundação Salim Farah Maluf/T.A. Queiroz, 1995. p. 280-290.

INSTITUTO DE PESQUISAS TECNOLÓGICAS (São Paulo, SP). Mapa geológico do Estado de São Paulo : escala 1:500.000. São Paulo, 1981. v.1. (IPT. Monografia, 6).

KOFFLER, N.F.; CAVALLI, A.C.; CHIARINI, J.V.; NOGUEIRA F.P. Inventário canavieiro com auxílio de fotografias aéreas. Piracicaba : PLANALSUCAR, 1979. 38p.

PINTO, S.A.F.; VÁLERIO FILHO, M.; GARCIA, G.J. Utilização de imagens TM/Landsat na análise com- 
parativa entre dados de uso da terra e de aptidão agrícola. Revista Brasileira de Ciência do Solo, Campinas, v.13, n.1, p.101-110, jan./abr. 1989.

POLITANO, W.; CORSINI, P.C.; LOPES, L.R.; SACCHI, E.; PARO, P.S. Caracterização por fotointerpretação da ocupação do solo no município de Monte Alto, SP. Engenharia Agrícola, Botucatu, v.7, n.1, p.1725, 1983.

RABBEN, E.L. Fundamentals of photointerpretation In: AMERICAN SOCIETY OF PHOTOGRAMETRY (Washington, Estados Unidos). Manual of photographic interpretation. Washington, 1960. p.99-186.
SPAROVEK, G. (Coord.). Plano diretor da Microbacia do Córrego do Ceveiro: diagnóstico da situação, levantamento de problemas e propostas de solução. Piracicaba : ESALQ, 1991. v.1.

SPAROVEK, G.; LEPSCH, I.F. Diagnóstico de uso e aptidão das terras agrícolas de Piracicaba. In: TAUKTORNISIELO, S.M.; GOBBI, N.; FORESTI, C.; LIMA, S.T. (Eds.). Análise ambiental: estratégias e ações. São Paulo : Fundação Salim Farah Maluf/T.A. Queiroz, 1995. p.273-280.

VIEIRA, M.J. Solos de baixa aptidão agrícola: opções de uso e técnicas de manejo e conservação. Londrina : IAPAR, 1987. 68p. (IAPAR. Circular, 51). 